www.jmscr.igmpublication.org

Index Copernicus Value: 79.54

ISSN (e)-2347-176x ISSN (p) 2455-0450

crossref DOI: https://dx.doi.org/10.18535/jmscr/v7i4.140

$\underline{\text { Research Article }}$

\title{
A comparative efficacy of 7.5 lakh units versus 1.5 million units of streptokinase in acute myocardial infarction in elderly patients
}

\author{
Dr Vinod Kumar ${ }^{1}$, Dr Ritu Bhagat ${ }^{2 *}$, Dr Roopali Jandyal ${ }^{3}$ \\ ${ }^{1}$ Consultant Physician JK Health Services \\ ${ }^{2,3}$ Senior-Resident Department of Pathology, GMC Jammu \\ *Corresponding Author \\ Dr Ritu Bhagat \\ Email: ritubhagat8600@gmail.com
}

\begin{abstract}
Introduction: In developing nations as in India, as the life expectancy has increased, more and more elderly patients having ischemic heart disease are being diagnosed and treated.

Aim: The objective is to evaluate whether thrombolysis with a lower dose of 7.5 lakh units of streptokinase was as efficacious as with streptokinase in conventional doses of 1.5 million units in achieving reperfusion of the infarct related coronary artery.

Material and Methods: The present study was conducted in elderly patients aged more than 65 years over a period of one year from nov.2016 to oct.2017 at GMC, Jammu which is a tertiary care centre. Sixty elderly patients with acute myocardial infarction were enrolled in the study, presenting within 12 hours of onset of symptoms and having no contra-indication to thrombolytic therapy.

Results: Out of the total 60 cases included in our study, 30 (50\%) were assigned to the study group and 30 $(50 \%)$ were included in the control group.

Conclusion: in the present study, we conclude that low dose (7.5 lakh units) of streptokinase was as effective as the standard dose (1.5 million units) of streptokinase in achieving reperfusion of the infarct related coronary artery, in the elderly patients of acute myocardial infarction.

Keywords: acute myocardial infarction, coronary artery, streptokinase, thrombolysis.
\end{abstract}

\section{Introduction}

Myocardial infarction is a frequent catastrophic cardiovascular event encountered in the setting of our hospital emergency rooms and coronary care units. Despite impressive studies in diagnosis and management over the last three decades, acute myocardial infarction (AMI), continues to be a major public health hazard in the industrialized world. Each year approximately 900,000 persons in the United States experience AMI and about
225,000 of them die. At least one-half of these patients die within 1 hour of onset of symptoms and before reaching the hospital emergency department ${ }^{1}$. A steady decline in mortality rate from AMI has been observed across several population groups since $1969^{2}$. In mid 1960 the concept of coronary care unit [CCU] was introduced. Subsequently, introduction of the pulmonary artery balloon flotation catheter set the stage for bedside hemodynamic monitoring and 
more precise management of heart failure and cardiogenic shock associated with AMI. The modern reperfusion era of coronary care was ushered in by intra-coronary and then intravenous thrombolysis, increased use of aspirin and development of percutaneous transluminal coronary angioplasty [PTCA] for AMI ${ }^{3}$. AMI has been found to be the leading cause of death in elderly over the age of 65 years. It accounts for $80 \%$ of deaths in the elderly, with $6.8 \%$ of the population of India over 60 years. The mortality in elderly is two-times more after AMI as compared to the younger counterparts ${ }^{4}$. Though the traditional dose of streptokinase fixed at 1.5 million units ${ }^{5}$, has been widely accepted, some recent clinical trials have provided non-invasive evidence of reperfusion with half dose streptokinase with comparable results. ${ }^{6,7}$

\section{Material and Methods}

The present work is a hospital based crosssectional study for a period of one year from nov.2016 to oct.2017 that included 60 patients of acute myocardial infarction in elderly that presented within 12 hours of onset of symptoms and had no contraindication to administration of streptokinase for thrombolysis. The patients were randomized into two groups: the study group to whom 7.5 lakh units of streptokinase was administered intravenously over 30 minutes, while the control group received the standard dose of 1.5 million units of streptokinase intravenously over one hour. Detailed history was taken and thorough clinical and biochemical profile was done.AMI was diagnosed by criteria defined by World Health Organization (WHO).

\section{Results}

The present study titled "Comparative efficacy of 7.5 lakh unit versus 1.5 million units of streptokinase in acute myocardial infarction in elderly patients" was conducted in Postgraduate Department of Medicine, Government Medical College Hospital, Jammu from November 2016 to October 2017. All the patients included in the study had presented within 12 hours of onset of symptoms and had no contraindication to administration of streptokinase for thrombolysis. The observations made were considered as follows:

Table 1: Gender wise distribution of cases

\begin{tabular}{|l|c|c|c|}
\hline \multirow{2}{*}{ Subjects } & \multicolumn{2}{|c|}{ Gender } & \multirow{2}{*}{ Total } \\
\cline { 2 - 3 } & Male No. (\%) & Female No. (\%) & \\
\hline Study group & $21(70.0)$ & $9(30.0)$ & $\mathbf{3 0}(\mathbf{1 0 0 . 0})$ \\
\hline Control group & $25(83.3)$ & $5(16.7)$ & $\mathbf{3 0}(\mathbf{1 0 0 . 0})$ \\
\hline Total & $\mathbf{4 6}(\mathbf{7 6 . 7})$ & $\mathbf{1 4}(\mathbf{2 3 . 3})$ & $\mathbf{6 0}(\mathbf{1 0 0 . 0})$ \\
\hline
\end{tabular}

Table 2: Distribution of Killip Class at presentation in the study group versus control group

\begin{tabular}{|l|c|c|c|c|}
\hline \multirow{2}{*}{ Subjects } & \multicolumn{3}{|c|}{ Killip Class } & \multirow{2}{*}{ Total } \\
\cline { 2 - 4 } & Class I & Class II & Class III & \\
\hline Study group & $23(76.7)$ & $7(23.3)$ & - & $30(100.0)$ \\
\hline Control group & $10(33.3)$ & $18(60.0)$ & $2(6.7)$ & $30(100.0)$ \\
\hline Total & $33(55.0)$ & $25(41.7)$ & $2(3.3)$ & $60(100.0)$ \\
\hline
\end{tabular}

Table 3: Distribution of coronary risk factors in study group versus control group

\begin{tabular}{|c|c|c|c|}
\hline Risk factors & $\begin{array}{l}\text { Study group }_{\text {30) No. }(\%)}(n= \\
\end{array}$ & $\begin{array}{c}\text { Control group } \\
\text { 30) No. }(\%)\end{array} \quad(\mathbf{n}=$ & 'p'-value (z-test) \\
\hline Smoking & $18(60.0)$ & $20(66.67)$ & $0.352 \mathrm{NS}$ \\
\hline Hypertension & $16(53.33)$ & $14(46.67)$ & $0.358 \mathrm{NS}$ \\
\hline Diabetes & $8(26.67)$ & $4(13.33)$ & $0.180 \mathrm{NS}$ \\
\hline Family H/o CAD & $6(20.0)$ & $8(26.67)$ & $0.333 \mathrm{NS}$ \\
\hline Hyperlipidemia & $4(13.33)$ & $12(40.0)$ & $0.493 \mathrm{NS}$ \\
\hline
\end{tabular}


Table 4: Comparative evaluation of therapeutic window to thrombolysis and time to pain relief in study group and control group

\begin{tabular}{|l|c|c|}
\hline & \multicolumn{2}{|c|}{ Mean \pm Standard Deviation } \\
\hline Subjects & Therapeutic window (hours) & Time to pain relief after STK (hours) \\
\hline Study group & $6.32 \pm 2.23$ & $5.90 \pm 4.76$ \\
\hline Control group & $4.90 \pm 1.96$ & $5.61 \pm 3.36$ \\
\hline
\end{tabular}

Table 5: Comparative evaluation of reperfusion using single non-invasive criterion-fractional change on ECG in study group versus control group

\begin{tabular}{|l|c|c|c|}
\hline Fractional change (Fc) & $\begin{array}{c}\text { Study group (n=30) } \\
\text { No. }(\%)\end{array}$ & $\begin{array}{c}\text { Control group }(\mathbf{n}=\mathbf{3 0}) \\
\text { No. }(\%)\end{array}$ & 'p'-value $\left(\chi^{2}\right.$-test) \\
\hline$\geq 0.5$ & $26(86.7)$ & $24(60.0)$ & \multirow{2}{*}{$0.2 \mathrm{NS}$} \\
\hline$<0.5$ & $4(13.3)$ & $6(20.0)$ & \\
\hline
\end{tabular}

Table 6: Comparative evaluation of reperfusion by single non-invasive criterion - time from completion of STK infusion to peak CPK-MB in study group versus control group

\begin{tabular}{|l|c|c|c|c|}
\hline $\begin{array}{l}\text { Time to peak } \\
\text { (hours) }\end{array}$ & CPK-MB & $\begin{array}{c}\text { Study group } \\
\text { 30) No. }(\%)\end{array}$ & $\begin{array}{c}\text { Control group } \\
(\mathbf{n}=\mathbf{3 0}) \text { No. }(\%)\end{array}$ & $\begin{array}{c}\text { 'p'-value }\left(\mathbf{X}^{2}-\right. \\
\text { test })\end{array}$ \\
\hline 0 to 12 & $22(73.3)$ & $18(60.0)$ & \multirow{2}{*}{$0.06 \mathrm{NS}$} \\
\hline$\geq 12$ & $8(26.67)$ & $12(40.0)$ & \\
\hline
\end{tabular}

Non-significant

Table 7: Comparison between reperfusion by combined criteria -fractional change and time from STK to peak CPK-MB in study group versus control group

\begin{tabular}{|c|c|c|c|c|c|}
\hline \multirow[b]{2}{*}{$\begin{array}{l}\text { Time from STK to peak CPK- } \\
\text { MB (hours) }\end{array}$} & \multicolumn{2}{|c|}{ Study group $(\mathbf{n}=\mathbf{3 0})$} & \multicolumn{2}{|c|}{ Control group $(n=30)$} & \multirow{2}{*}{$\begin{array}{l}\text { 'p'- value } \\
\left(\chi^{2}-\text { test }\right)\end{array}$} \\
\hline & $\begin{array}{c}\mathrm{Fc} \geq 0.5 \\
\text { No. } \\
(\%)\end{array}$ & $\begin{array}{c}\text { Fc }<0.05 \\
\text { No. } \\
(\%)\end{array}$ & $\begin{array}{l}F c \geq 0.5 \\
\text { No. }(\%)\end{array}$ & $\begin{array}{c}\mathrm{Fc}<0.05 \\
\text { No. }(\%)\end{array}$ & \\
\hline 0 to $<12$ & $22(73.3)$ & (1) & $\begin{array}{c}16 \\
(53.3)\end{array}$ & $2(6.7)$ & \multirow[t]{2}{*}{$0.13 \mathbf{~ N S}$} \\
\hline 12 to 24 & $4(3.3)$ & $4(13.3)$ & $8(26.7)$ & $4(13.3)$ & \\
\hline
\end{tabular}

NS = Non-significant

Table 8: Comparison between complications following streptokinase infusion in study and control groups

\begin{tabular}{|l|c|c|c|}
\hline Complications & $\begin{array}{c}\text { Study group } \\
(\mathbf{n}=\mathbf{3 0}) \text { No. }(\%)\end{array}$ & $\begin{array}{c}\text { Control group }(\mathbf{n}=\mathbf{3 0}) \\
\text { No. }(\boldsymbol{\%})\end{array}$ & $\begin{array}{c}\text { p-value } \\
(\text { Z-test })\end{array}$ \\
\hline Minor bleed & - & $\mathbf{2}(\mathbf{6 . 6})$ & $\mathbf{0 . 0 1 6}$ \\
\hline Major bleed & - & - & - \\
\hline Anaphylaxis & - & - & - \\
\hline Hypotension & - & - & - \\
\hline
\end{tabular}

Table 9: Comparison between occurrence of post-myocardial infarction (Ml) angina in study group versus control group

\begin{tabular}{|l|c|c|c|}
\hline \multirow{2}{*}{ Subjects } & \multicolumn{2}{|c|}{ Post MI angina } & Total \\
\cline { 2 - 3 } & Negative No. $(\%)$ & Positive No. $(\%)$ & No. $(\%)$ \\
\hline Subject group & $28(93.3)$ & $2(\mathbf{6 . 7})$ & $30(100.0)$ \\
\hline Control group & $30(100.0)$ & - & $30(100.0)$ \\
\hline Total & $\mathbf{5 8}(\mathbf{9 6 . 7})$ & $\mathbf{2 ( 3 . 3 )}$ & $\mathbf{6 0}(\mathbf{1 0 0 . 0})$ \\
\hline
\end{tabular}

\section{Discussion}

The present study titled "Comparative efficacy of 7.5 lakhs units vs 1.5 million units of streptokinase in acute myocardial infarction in elderly patients was conducted in a prospective manner in Postgraduate Department of Medicine, 
Government Medical College Hospital, Jammu over a period of one year. Sixty elderly patients with acute myocardial infarction were enrolled in the study, presenting within 12 hours of onset of symptoms and having no contra-indication to thrombolytic therapy. The patients included in the study were randomized into two groups - 30 patients in the study (cases) group were thrombolysed with 7.5 lakh units of streptokinase (half dose) over thirty minutes while the rest 30 patients in the control group were administered 1.5 million units of streptokinase (conventional full dose) over one hour.

The mean time to pain relief from streptokinase infusion in the study group (cases) was $5.90 \pm$ 4.75 hours compared to $5.61 \pm 3.22$ hours in the entire control group. $73.33 \%$ (22) of patients had complete pain relief within 6 hours of completion of streptokinase infusion in the study group (cases), 60\% (18) of the patients had complete pain relief within 6 hours of completion of streptokinase therapy in the control group. There was no statistically significant difference between the two groups by Z-test $(p=0.219)$. In the subset of patients having pain relief within 6 hours of completion of streptokinase infusion, the mean time in the study group (cases) was 4.136 hours compared with 3.22 hours in the control group, the difference of which was not significant. This was comparable with the studies of Sivan et al. $(2003)^{8}$ and Ahmed et al.(1992) ${ }^{6}$. Reperfusion is characterized by a rapid progressive decrease in pain intensity within 30 minutes of onset of its abatement (Shah et al., 1993) ${ }^{9}$. However, this is a subjective phenomenon and no definite time period has been documented to signify reperfusion.

Reperfusion using the criterion of fractional change (Fc) on ECG was achieved in $86.67 \%$ (26) and $80 \%$ (24) of the patients in the study and the control group, respectively. The difference between the two groups by chi-square test was $\mathrm{p}=$ 0.2 , which is not statistically significant. According to fractional change, the patients were said to be reperfused if $\mathrm{Fc} \geq 0.5$ and not reperfused if $\mathrm{Fc}<0.5$. A fractional change value of $\mathrm{Fc} \geq 0.5$ had been found to $67 \%$ ) specific and $93 \%$ sensitive for predicting a patent artery (Hogg et al., 1988) ${ }^{10}$.

The mean time to peak CPK-MB was observed to be $9.47 \pm 2.25$ hours in the entire study group (cases) and $9.47 \pm 2.58$ hours in the entire control group. When reperfusion was assessed by early peaking of CPK-MB within 12 hours, $73.33 \%$ ) (22) and 60\%) (18) of the patients were reperfused in the study and control groups, respectively. No statistically significant difference was found in the two groups by chi-square test $(\mathrm{p}=0.057)$. The mean time to peak CPK-MB in those reperfused by this criterion in both the groups in combination was 9.04 hours compared with 11.6 hours in those not reperfused. This observation and result of our study was comparable to that of Gottlich et al. $(1988)^{11}$. There was a significant difference between the two groups with p-value of 0.031 . This indicated that serum CPK-MB

levels peak earlier in the reperfused than the nonreperfused group. Isoforms of creatine kinase (CPK-MB) are a reliable plasma marker of myocardial necrosis. It has been observed that CPK-MB levels peak earlier when there is reperfusion of the occluded coronary artery. The time from streptokinase infusion to peak CPK-MB of less than 12 hours has been said to signify reperfusion, while peaking at 18 or 24 hours represents that no reperfusion has taken place, as proved angiographically. This demarcation segregated patients with and without reperfusion and yielded a sensitivity of $95 \%$ and specificity of $88 \%$ (Alderman et al, 1984) $^{12}$. In a study taking time from streptokinase infusion to peak CPK as a criterion for reperfusion, it was found that peaking of CPK occurred at $9.7 \pm 6.3$ and $12.3 \pm 4.8$ hours in those receiving 7.5 lakh units and 1.5 million units of streptokinase, respectively (difference not statistically significant) (Gottlich et al, 1988) ${ }^{11}$. In this study, in the group receiving, 7,50,000 IU of streptokinase, $89 \%$ ) patients showed peaking of CPK-MB within 12 hours, while $67 \%$ of patients 
did so in the group given $1.500,000$ IU. This compares well with the data of the present study. The study has shown that in a dose-related comparison of thrombolytic therapy, there was no significant difference in the number of patients reperfused by non-invasive criteria, singly and in combination between the group receiving 7.5 lakh units of streptokinase (study group) and 1.5 million units of streptokinase (control group). Dose ranging studies of thrombolysis and streptokinase have yielded similar comparable results using variable criteria for assessing reperfusion (Gottlich et al. 1988 ${ }^{11}$; Six et al. 1990 ${ }^{13}$; Ahmed et al. 1992 ${ }^{6}$; Bose et al. $1996^{7}$ ).

Ahmed et al. (1992) ${ }^{6}$ in their study used both CPK-MB and rapid resolution of ST-segment elevations as evidences of reperfusion while comparing half-dose streptokinase $\quad(7,50,000$ units) regimen with the conventional full dose (15 lakh units) regime. The results of their study were in concordance with our study, wherein they concluded that a dose of 750,000 units of streptokinase was clinically satisfactory in coronary reperfusion and produced results similar to those reported previously with 1.5 million units of streptokinase.

The results of our study also corroborate with those of Sivan et al (2003) ${ }^{8}$ who analyzed the efficacy and safety of streptokinase in full conventional dose (15 lakh), half dose (7.5 lakh) and no thrombolysis in the elderly population (> 75 years). Successful thrombolysis in their study was defined as ST-segment resolution of $50 \%$ or more. They concluded that half dose (7.5 lakh units) streptokinase has equal efficacy, better clinical outcome, and reduced rate of complications compared to full dose (15 lakh) streptokinase. Of all the 60 patients, 34 (56.6\%) patients reperfused by Fc criterion had therapeutic window less than 6 hours as compared with 16 $(26.67 \%>)$ patients having therapeutic window of 6-12 hours. Significant statistical difference was observed in the two subsets $(\mathrm{p}=0.026)$. Similarly, $28(46.6 \%>)$ and $12(20 \%)$ patients reperfused using the criteria of early CPK-MB peaking within 12 hours had therapeutic window less than 6 and 6-12 hours, respectively, p-value for difference between the two groups was 0.007 , which was statistically significant. Patients who are given thrombolytics earlier following onset of symptoms obtain reperfusion in a greater proportion of patients. This is also validated and supported by studies that have shown that older thrombi are more resistant to lysis (Karsch et al. $1983)^{14}$. According to AHA/ACC guidelines for management of acute myocardial infarction, therapeutic window should be less than 12 hours (Ryan et al 1996) ${ }^{15}$, though the rates of reperfusion was $60-70 \%$ in studies that delayed treatment for more than 6 hours after onset of chest pain (Anderson et al 1984

\section{Conclusion}

In the present study, we conclude that low dose (7.5 lakh units) of streptokinase was as effective as the standard dose (1.5 million units) of streptokinase in achieving reperfusion of the infarct related coronary artery, in the elderly patients of acute myocardial infarction. Also, low dose streptokinase (7.5 lakh units) infusion was found to be associated with a lower incidence of haemorrhagic complications as compared to 1.5 million units of streptokinase infusion.

\section{Bibliography}

1. Muller DWM, Topol and Blood Institute. Morbidity and mortality chartbook on cardiovascular, lung and blood diseases, Bethesda. Md: US Department of Health and Human Services, Public Health Service, National Institute of Health; May 1992.

2. Gheorghiade M, Razumma O, Borzak S et $a L$ Declined in the rate of hospital mortality from acute myocardial. Impact of changing management strategies. Am Heart J1996; $131: 250$.

3. Rentrop KP. Restoration of anterograde flow in acute myocardial infarction. The 
first 15 years. J Am Coll Cardiol 1995; 25: 13.

4. Chopra KL. Thrombolytics and antithrombotics for acute coronary syndromes in the elderly. The Cardio Thoracic J1996; 2 (4) : 9-13.

5. Shroeder R. Intravenous short-term infusion of streptokinase in acute myocardial infarction. Circulation 1983; 67 : 536-581.

6. Ahmed, I. ECG and enzymatic indicators of therapeutic success after intravenous streptokinase for acute myocardial infarction - a pilot study. JPakMedAss 1992; 42 (12) : 288-290.

7. Bose CC, Balkrishan S, Satyavarthy et al. Prospective study of safety and efficacy of 7.5 lakh units STK in AMI in Indian patients. Thrombolysis Update 1996; 4 (3) : 7-11.

8. Sivan R, Chockalingam V, Subramanian T et al Comparative study of 7.5 lakh and 15 lakh units of streptokinase therapeutic issues in an elderly population with acute myocardial infarction. Indian Heart $J$ 2003; 55 (5) : 149.

9. Shah PK, Cercek B, Lew AS et al Angiographic validation of bedside markers of reperfusion. J Am Coll Cardiol 1993; 21 : 55. Sherry S, Alkajaersig N, Feather AP. Fibrinolysis and fibrinolytic activity in man. Physiol Rev 1959; 3:515.

10. Hogg KT, Hornung RS, Howie CA et al. Electrocardiographic prediction of coronary artery patency after thrombolytic treatment in acute myocardial infarction: use of the ST segment as non-invasive marker. Br Heart 1988; 60 : 275-280.

11. Gottlich C, Cooper B, Chumacher JR et al Do different doses of intravenous streptokinase after the frequency of coronary reperfusion in acute myocardial infarction? Am J Cardiol 1988; 62 : 843846.
12. Alderman EL, Jutzy KR, Berte LE et aL Randomized comparison of intravenous versus intracoronary streptokinase for myocardial infarction. Am J Cardiol 1984; $54: 14$.

13. Six AJ, Louwerenburg HW, Braams R et al $A$ double-blind randomized multi-center dose-ranging trial of intravenous streptokinase in acute myocardial infarction Cor Art Dis 1990; 65 (3) : 119123.

14. Karsch KR, Hofmann M, Rentrop KP et $a L$ Thrombolytic in acute experimental myocardial infarction. J Am Coll Cardiol $1983 ; 1: 427$.

15. Ryan TJ, Anderson L, Antman EM et al ACC/AHA Guidelines for the management of patients with acute myocardial infarction. J Am Coll Cardiol 1996; 28 (5) : 1328-1428. 